\title{
Not a Film, but an Object: Emotional Politics of Appreciating Badfilm
}

\begin{abstract}
The films embraced by the viewers due to their formal and/or aesthetic incompetence (e.g. technical flaws, lousy acting, cheap special effects, baffling storylines) are called "so bad, it's good," "goodbad film" or simply "badfilm". Badfilm, which constitutes a form of subcultural counter-aesthetics, overthrows traditional hierarchies of taste. Despite being positioned at the lowest end of film industry, badfilms are mostly embraced by cinephiles who seem to believe they have good taste. In order to elaborate on this paradoxical case, this article suggests that the cult interest in badfilms relies to a great extent upon emotional engagement. Through analyses of textual and extratextual features of Fateful Findings (Neil Breen, 2013), in conjunction with its various receptions, the badfilm appreciation will be investigated. Neil Breen's films are championed by virtue of their massive failures. They make viewers think of the films as artifacts rather than story-worlds. As a conclusion, the meta-level emotional responses called "artifact emotions" (Tan, Plantinga), due in no small part to "schadenfreude" (enjoyment derived from the troubles or failures of others) provide a basis for the collective appreciation of badfilms.
\end{abstract}

Keywords: Badfilm, cult cinema, cinematic emotion, artifact emotions, schadenfreude.

"I do not give a star rating to Pink Flamingos, because stars seem not to apply. It should be considered not as a film but as a fact.

Or perhaps as an object.”

(Ebert 202)

\section{Introduction}

The concept of 'cult film,' which is believed to differ from mainstream cinema in terms of both textual features and reception habits, brings with it some dilemmas. The fact that it covers a wide range,

\section{Mehmet SARI}

Istanbul University

mehmetsari@gmail.com

EKPHRASIS, $1 / 2021$

COUNTERDISCOURSES AND

COUNTERPUBLICS IN CINEMA, ART,

MEDIA AND LITERATURE

pp. 70-85

DOI: $10.24193 /$ ekphrasis. 25.6

Published First Online: June 21, 2021 
from commercially failed big budget productions to the films that are aesthetically described as 'trash,' causes this concept to be ambiguous. What are defined as the characteristics of the cult film are not the features of each cult film, but instead they include various narrative qualities and processes that differ from film to film. Neither aesthetic properties nor viewing practices alone are enough to make a film cult. But one thing is sure. It is not quite reasonable to talk about an 'individual cult': for something to be a cult it must have a certain number of followers. As Kawin notes, "the cult film can be defined primarily in terms of its acceptance: it is a movie with a following" (18). When a personality, object or an artwork has achieved a cult status, a subcultural meaning rises to the surface. At the heart of this concept are cultures' efforts to express themselves and their opposition to social norms. In this subcultural context, one type of cult film bears a unique significance.

Due to their poor qualities, some films are considered 'so bad,' that this badness begins to create an appreciation on another level. This situation is defined as 'so bad, it's good,' or simply 'badfilm'. 'The phrase is commonly used for films like Plan 9 from Outer Space (Ed Wood, 1957), Miami Connection (Woo-sang Park and Y.K. Kim, 1987), Troll 2 (Claudio Fragasso, 1990), Samurai Cop (Amir Shervan, 1991), The Room (Tommy Wiseau, 2003) or Birdemic: Shock and Terror (James Nguyen, 2010). Each of these films gained a cult following and created a 'midnight movie' phenomenon. They are beloved just because they fail so spectacularly. To summarize briefly, notwithstanding (or as a result of) the creators of these films having lofty ambitions, the films fail in almost every aspect; therefore they attract viewers' attention.

This paper examines the formation of badfilm which offers a particular aesthetic experience. As Weiner argues, films like Birdemic "drop us into a murky vortex of authorial intent, sabotage some of our most basic notions about character and narrative, and remind us of film's power to disturb, disorient, and discombobulate us" ("The Worst Movies"). It is worthy to explore why some badfilms can stand out from other bad films and take the stage. How come these so called 'worst' films fascinate viewers and shine amongst thousands of other badly made films? In order to make an inquiry of this large-scale problem, specific features of and viewing strategies for a selected film can be evaluated together. If viewers praise these utter disaster films, it is important to ask what their praise consists in.

The viewers have idiosyncratic relations with cult films. Every cult appreciation of a film exists in the special bond between the film and viewers. Cult films generally depend on the emotional investment they generate. The ultimate satisfaction that some viewers experience in relation to badfilms in particular creates a kind of paradox. How does an aesthetically disaster film merit appreciation? This paper elaborates upon the motivation and the emotional investment of viewers in a badfilm, in the context of film-elicited emotions, by investigating the example of Fateful Findings (Neil Breen, 2013). 
Over the past decade, filmmaker Neil Breen acquired fame in the badfilm arena, and his films were taken up by film-buffs. The transformation of most of his films from ordinary bad films into cult artifacts merits attention and inspection. Geraghty asserted that, "the subcultural value of the film to its perceived viewers - the fans-is what needs to be analysed and discussed to really get an appreciation of film as cultural artifact" (103). I argue that the subcultural attention and viewer engagement with Neil Breen's films depend on the affective appeals they offer. As such, I aim to understand how a subculture of badfilm evolves within the YouTube community. Kolb draws a conclusion from related sociological research and claims that emotions about cultural products can be directly associated with distinctness and the uniqueness of a subculture. Thus, I claim that the cognitive approaches to cinema can help explaining a badfilm's emotional appeal. Plantinga also highlights the importance of cognition in film viewing: "The film spectator is constantly monitoring, comprehending, making inferences, estimating, anticipating, and evaluating" ("Putting Cognition" 146). Although he refers to standard narrative films and their audience, these activities seem more suitable for cult film audiences. In addition to this, the concept of "paracinema," which champions bad taste and excess in cinema, will be used in this study. As specified by Sconce, "[r]egardless of their individual interests and ultimate allegiances, however, the paracinematic audience cultivates an overall aesthetic of calculated disaffection, marking a deviant taste public disengaged from the cultural hierarchies of their overarching taste culture" (“'Trashing' the Academy" 376). Furthermore, the paracinematic reading of a film could reveal the centrality of cognition in film reception.

\section{Towards an Understanding of Badfilm}

It would not be wrong to say that most of the art is 'boring,' or at least mediocre, considering the abundance of artworks produced in history. Only a few of them could have a significant place in their canon. In the context of cinema, from a historical perspective, and according to surveys of critics and the public or to festival awards, some films are considered as major classics. Screenwriter Richard Walter sketches out this fact: „People say why don't they make good movies now like they used to in the ' 30 s and the ' 40 s. Did they make good movies in the '30s and the '40s? Yes, they did, there were a lot of really good ones. But there were also a lot, a lot of lousy ones, we just don't remember them" (Film Courage 02:33-02:47).

The films that Walter talks about are forgettable, mediocre films. Mediocre films have many similarities to each other, so it becomes difficult for the viewers to find something appealing or idiosyncrasy in them. Most of the characteristics are predictable or formulaic. However, these films execute the minimum standards of filmmaking. When the level of 'lousiness' starts to drop, one can begin to mention certain film categories like 'trash film,' 
'camp' or 'Z-movie.' So many things that we take for granted in films (lighting, sound mix, editing, etc.) start to deteriorate. Same filtering mechanism exists in this circle of films with lower qualities too. When a film turns out to be that bad, it starts to catch viewers into the whirlpool of interest. The aforementioned films like The Room or Birdemic fall into this category. Bray underlines their prominent characteristics: "But would we still be watching Plan 9 or any of the rest of them today if the film-makers had dodged these pitfalls and premiered run-of-the-mill movies? Cinema history is littered with the unmarked graves of bad films, but they don't all wobble. It's the flaws that make them memorable, that help them attain legend status" (“One-star Wonders”).

The relationship between cinema and badness has various implications. According to Bartlett badness can refer to "aesthetically or morally" badness, or "critically disreputable" (40) qualities of a film. Thereupon, she briefly encapsulates the definition of badness: "films that are identified, distinguished, and potentially valued for their incompetence and technical failure" (40).

Badfilm is a "recognized and large category of cult" (Hunter 485). Badfilms are produced inadvertently, since trying to make a 'bad' artwork knowingly and willfully seems absurd. Therefore, the badness of these films is assigned by viewers. Badfilms highlight the fact that the viewers' reactions take an important place in determining the value of a film. Thus, a paradox emerges in regard to success and failure. Hoberman asserts that "a supremely bad movie —an anti-masterpiece-projects a stupidity that's fully as awesome as genius" (9). Hunter identifies "badfilm" where its badness "is not a mere summary of critical disapproval, but denotes a complete abrogation of the minimum standards of filmmaking” (487).

Badfilms are not solely cultural products ready for consumption; rather, they provide a great opportunity to delve into topics such as the functioning of the film industry and the intrinsic value of films. Badfilms are preferred by the viewers by virtue of their ostensible opposition to mainstream. Viewers who devote themselves to badfilms constitute a cinematic subculture. As Thornton briefly summarizes, the term subculture refers to "groups of people that have something in common with each other (i.e. they share a problem, an interest a practice) which distinguishes them in a significant way from members of other social groups" (1). The badfilm enthusiasts provide added-value to films that are ignored by or excluded from mainstream culture.

In 1995, film scholar Jeffrey Sconce coined a new term that comprises films dismissed as bad, called "paracinema." Paracinema-a culture of counter-taste in which the hierarchies are denied and that includes many non-mainstream genres-exists as a reaction to the understanding of taste by the elite, the cultural bourgeoisie. Thus, films that are evaluated as bad according to general film criteria are, nevertheless, valued aesthetically and artistically due to the understanding of paracinema. Films that fall into this category are generally not included in areas considered worth studying, at least according to dominant artistic values. 
Sconce asserts that paracinema is "less a distinct group of films than a particular reading protocol, a counter-aesthetic turned subcultural sensibility, devoted to all manner of cultural detritus" (“'Trashing' the Academy” 372). Sconce adds "badfilm”- a term which seems to be adopted from Zontar fanzine-into the subgenres of paracinematic culture, and provides the following explanation of paracinema: "In short, the explicit manifesto of paracinematic culture is to valorize all forms of cinematic 'trash,' whether such films have been either explicitly rejected or simply ignored by legitimate film culture" ("Trashing' the Academy" 372). Through this reading strategy, it becomes possible to champion the 'worst' films as masterpieces. Anything that can be seen as a mistake in a film under 'normal' conditions gains value in this context.

Just as it is difficult to give a precise definition of "cult film" and delineate in detail the films included in this category, the "badfilm" category cannot be described unambiguously. A midnight movie like El Topo (Alejandro Jodorowsky, 1970), a Hollywood classic like Casablanca (Michael Curtiz, 1942), or a mainstream blockbuster like Titanic (James Cameron, 1997) are considered cult films for different reasons. However, considering the common features that films classified together share, badfilms belong to a more distinct category. Identifying a badfilm mostly stems from the aesthetic attitude of paracinema. As a counter-taste, paracinema moves away from cult cinema's emphasis on fandom and brings excess and bad taste forward.

Organically bad-or, in Hoberman's terms, "objectively bad"—-these films resemble nothing else but themselves. As a pivotal feature of paracinematic subculture, the code of authenticity works in various ways. In order to be discovered, the badfilm elements require the activity of viewers. Badfilm viewers do not passively experience these films; they seek for some aspects that appeal to them. They often have a remarkable ability to sense sincerity and authenticity. Hunter states that "pleasure is in fact, for devotees, diminished with Badfilms if there is a suspicion that a film is actually meant to be bad or camp" (487). In this respect, the referred 'pleasure' constitutes the main problem of this study. I argue that the goodness of a badfilm stems from the pleasure it elicits in the viewers. With the help of a cognitive approach, I'll try to explain what that pleasure consists in, and its relation with authenticity.

One way to look at the audience's relationship with films is through emotions. According to Hunter, cult films are "defined by their audiences' enthusiasm and emotional investment rather than by stable textual markers" (484). Evaluating these films as good (or pleasurable) because they are "so bad," indicates the emotion of "schadenfreude." Schadenfreude is a German word expressing the emotion of being joyful about someone else's misery, or a misfortune that has happened to them. It is an emotion that brings to attention issues such as justice, conscience, love and jealousy in human relations. It can also be categorized as a "specific and seemingly atypical type of joy" (Van Dijk and Ouwerkerk 7). The reasons for enjoying others' misfortunes can be various. By hinging upon empirical studies, the authors 
claim that "deservingness," "envy" and "self-enhancement" constitute three major concerns that underlie schadenfreude. Yet, the main reason for it could be the need (or the desire) to feel superior to others.

In the context of badfilm, schadenfreude appears as a discursive practice. Kolb has noted that "to belong to an emotional subculture is not a passive achievement" (1232). Badfilm enthusiasts perform schadenfreude as a practice of reception. As more viewers comment on films and show their reaction owing to social media, the way films are perceived and the emotions the films elicit have become more observable. Even when social media had not become widespread, Jancovich commented on cult groups and said that they are neither "spontaneous" nor "self-organizing," but are "brought together, and a sense of 'imagined community" is produced and maintained, through the media" (318). According to Sconce, the cult film phenomenon "has less to do with a body of work than with the emergence of a particular reading protocol, one wholly promiscuous in its choice of object and unified only by the relative homogeneity of the social formation from which it arises" ("Esper, the Renunciator" 31). In this paper, I argue that artifact emotions structure paracinematic reading protocols and that the social circles formed around the emotion of "schadenfreude" define the badfilm experience.

\section{A Work of "Sheer Breenius": Fateful Findings}

For more than 15 years, Neil Breen has been building a reputation for himself within the cult film community. He still continues to be mythologized by his followers. ${ }^{2}$ The primary reason is his barbarian approach to cinematic merits, decimating the conventional filmmaking rules, even though this is not his determined intention. Everyone of his films (Double Down, 2005; I Am Here... Now, 2009; Fateful Findings, 2013; Pass Thru, 2016; Twisted Pair, 2018) is utmost incomprehensible. Neither of them fulfills the minimum requirements of filmmaking. Hence, they share the transgressive nature of cult cinema. Breen has a place in the lineage of directors such as Ed Wood, James Nguyen and Tommy Wiseau: passionate, subduer, and delusional. According to one commentator, "compared to this guy, Tommy Wiseau is like Hitchcock" (The Flop House 10:46-10:50); and to another: "He makes Ed Wood's Plan 9 from Outer Space look like The Lord of the Rings, or at least The Hobbit" (Homeless Movies 00:41-00:46). The poorest qualities of his films bring him into prominence, yet he enunciates himself as a competent filmmaker.

Breen's films cannot be slotted into any particular genre, other than sheer badfilm. Their main theme is nearly identical. A middle-aged man with supernatural abilities wants to teach humanity a lesson about the evil in the world. After five films, it would not be wrong to say that Breen himself has a messiah complex. He plays the savior of humanity in every one of 
his films, being either a prophet or a deity-type person. He epitomizes the white heterosexual incompetent male filmmaker, while putting sincere efforts into producing apologues. His moral judgments are incomprehensible, but are delivered in a thought-provoking way, which makes viewers wonder about the underlying reasons for making such films. Many viewers ponder on his real purpose. For example one asks: "Is he trying to do The Room again, or is this coming from a genuine place?” (Nyx Fears 08:05-08:13). Putting the questions about his intentions aside, this paper's main interest is the appeal that his films have and the emotional motives that attract viewers around them.

In order to elucidate what sort of emotions does a badfilm elicit for the cooperative viewer, I will touch briefly on cinematic emotions. According to Tan, the emotions felt while watching a film are basically of two types. If the emotions are derived from the viewer's appraisal of the film's aims or characters, and from the viewer's immersion in the storyworld, we can refer to "fiction emotions" or "F-emotions." The content of the narrative creates "the illusion of being present in the fictional world" (Tan 52). Within this scope, the classical Hollywood style enables the "the diegetic effect." The ordinary responses to narrative films can be exemplified as happiness for Andy Dufresne, when he breaks out of prison in The Shawshank Redemption (1994), fear when Xenomorph crawls in the corridors of spaceship in Alien (1979), or concern for the protagonist Solomon Northup in 12 Years a Slave (2013). On the other hand, viewers don't always imagine themselves in the fictional narrative. Therefore, the film as an artifact plays another role in emotion.

For Plantinga, artifact emotions ("A-emotions") are "all of the emotional responses that can be solicited directly by the artefactual status of film, as opposed to the content of the fiction" (Moving Viewers 74). The film is being seen as a created artifact with regard to its expressive elements. Plantinga, who accepts Tan's distinction, exemplifies thus artifact emotions: "Artifact emotions may include disdain for the clumsy or stereotypical portrayal of a social type, or admiration and enthrallment for the expertise with which a difficult scene is constructed" (Screen Stories 109).

In his attempt at theorizing cult cinema, Sconce lays emphasis on non-diegetic elements which open up possibilities to discuss artifact emotions. He argues that, "by concentrating so intently on 'non-diegetic' elements in these films, be they unconvincing special effects, blatant anachronisms, or histrionic acting, the paracinematic reading attempts to activate the 'whole film' existing... alongside the narrative film we tend to think of ourselves as watching” ("'Trashing' the Academy” 387). Paracinematic reading of a badfilm provides an opportunity to reveal all of the aspects of filmmaking. The reasons why these films were made arouse great curiosity in the audience: "Faced with such overwhelming failure and incompetence, viewers are thus encouraged to look beyond the filmic text as a way of understanding what they are witnessing" (Bartlett 42). Thus, the badfilm devotees develop a kind of appreciation to make sense of the films. According to Tan's description, the appreciation of the artifact, which 
refers to "the motive that consists in finding enjoyment in formal film characteristics" (34), applies perfectly to the badfilm reception. Since there is not a chance of being imaginatively immersed within the narrative, in a badfilm experience the viewer's engagement is assured by artifact emotions. I argue that the density of these emotions causes a 'bad' film to turn into a 'good-bad' film. In order to examine this more closely, I'll analyze one of Neil Breen's films and its various receptions.

Neil Breen wrote, produced, directed, edited, even catered and starred in Fateful Findings, along with his other films. The film has many subplots lacking overall consistency. The main plot is summarized on IMDb as follows: "A computer-scientist/novelist reunites with his childhood friend, hacks into government databases, and faces the dire and fateful consequences of the mystical actions he obtained as a child" (Ross).

Unlike other badfilms, like Troll 2 (a poorly made horror film), The Room (a sloppy melodrama with a love triangle trope), or Birdemic (a failed homage to Hitchcock's Birds), Fateful Findings has no apparent connection with any other genre or film. In addition to this, all these badfilms have more or less stable storylines. Fateful Findings has an extremely convoluted storyline, which is nearly impossible to interpret. A YouTuber talks about it in a jeering manner: "It sounds like you are in a bar with some drunk guy and he is trying to tell his life story. And his life story sounds like he is the most amazing guy ever... After a while, you don't want the story to end just yet, you kind of want to see where this goes" (Nyx Fears 22:38-23:21).

I'll try to highlight the most important film features related to artifact emotions, in order to discuss the relative homogeneity of the emotions that Breen's film elicits. To this end, I'll examine various YouTube videos scrutinizing the whole film.

Like all fictional films, a badfilm creates tension through the events presented in its fictional world. However, contrary to other films, it does not try to eventualy resolve its uncertainty. Additionally, with its aesthetic incompetence, a badfilm leaves viewers discombobulated. Whereas a regular "bad film" elicits negative emotions (boredom, annoyance, disappointment, etc.) due to its various shortcomings, a genuine badfilm evokes complex emotions. The common reaction to a badfilm is, in a sense, a coping mechanism with the amorphous artifact encountered.

Fateful Findings, a case in point, is worth studying in this context. It seems as if all viewers had agreed and concentrated on one emotion. Acting with the emotion of schadenfreude, they take notice of even the tiniest details of a film, from beginning to the end. Their viewing strategies have an emotional modus operandi which functions as artifact emotions. While, at first glance, it may seem like a very fiendish emotion, recent studies have revealed that schadenfreude is complex. Feeling schadenfreude at a badfilm may have several reasons. The most visible reason is that the bad qualities of the film and/or the selfish narcissism of the filmmaker are getting their comeuppance. Viewers practically experience a sort of malicious 
joy in watching a badfilm. It almost becomes a contest of how many awful features or bizarre moments they can discover. Seeing a film so unskillfully made creates a "could have done better" feeling in viewers, therefore an ironic viewing strategy starts to take shape (Sarkhosh and Menninghaus 42).

One of the other prominent reasons could be schadenfreude's unific nature. Watt Smith notes that "schadenfreude may appear antisocial. Yet it is a feature of many of our most cherished communal rituals, from sports to gossip" (17). Badfilm enthusiasts bond with each other by concentrating their schadenfreude at a single film or a filmmaker. According to Watt Smith, one of the benefits of schadenfreude is paving the way for bonding between people over a "party-in-interest" (15). She continues to elaborate on this trait of the emotion: "It may seem misanthropic, yet it is enmeshed in so much of what is distinctly human about how we live: the instinct for justice and fairness; a need for hierarchies and the quest for status within them; the desire to belong to and protect the groups that keep us safe" (17). The displeasure of watching an unwatchable film is outweighed by the cognitive pleasures which ultimately lead to evaluating the film as 'good'

The pleasure is derived from artifact emotions. Tan uses the term "appreciation of the artifact" to refer to "the motive that consists in finding enjoyment in formal film characteristics” (34). Badfilm devotees generally appreciate the films by expressing pleasure (enjoyment). Performing the emotion becomes a subcultural act. As Sconce argues, badfilm appreciation is also "a politics of taste that operates somewhere between social negotiation and personal perversion" ("The Golden Age” 674). Commentators who review Fateful Findings fundamentally enact the "ironic reading strategies" of paracinema ("Trashing' the Academy” 536). Church underscores Sconce's subcultural approach: "[T]he 'so bad it's good' reading strategy, which privileges wild moments of excess, continuity errors, and other symptoms of film-making desperation, can be raised to the level of political critique by ironically celebrating the aesthetically 'worst' films as masterpieces of the medium” (14).

The evaluation of a badfilm usually starts with the beginning credits and ends with the final credits. Every single offbeat trait is being noticed. Viewers keep their eyes peeled for even the slightest shortcoming. Regarding Fateful Findings, even the distribution and the publicity of the film becomes an issue. Neil Breen has made each of his films available for sale on different websites, and he does not offer streaming. People can only buy DVDs by mail. The DVDs have no sleeves or covers, they come in a jewel case, and the discs are most probably burned by him on his home computer. This absurdity gives users an opportunity to make fun of it. In a reaction video, the viewers cheer while the ending credits are scrolling down (YourMovieSucksDOTorg 22:01-22:26). This is not just because nearly all of the work is done by Breen, but also because of the notice text at the end, which says "listed companies in the credits with an ' $\mathrm{N}$ ' or a ' $\mathrm{B}$ ' in their name are fictitious. This work was actually done personally by Neil Breen.” 
The features that people do not pay attention to in ordinary films, are fully exposed in badfilms. They pull away viewers from the so-called 'realism' of generic filmmaking. A user calls Fateful Findings an essential viewing for understanding professional cinema. Such amateur cinema helps people recognize the differences in "what makes a professional film and where that level of gloss comes from" (GenreVision 25:45-25:50). In the meantime, they broaden one's horizon, as Hoberman underpins: "anti-masterpieces break the rules with such exhilaration as to expand our definition of what a movie can be" (qtd. in Hunter 492). The same user reiterates this ability: "If you are somebody who really does just see mainstream theatrical releases, watch this movie, because you will see that there are so many other types of 'what the f...k' cinema out there. It will open your eyes to a brand-new world" (GenreVision 25:19-25:32). However, this trait of a badfilm is articulated usually in a mocking tone: "Everything in this movie is done at the lowest level of competency possible. But it's like in a great way. If I was trying desperately hard to make a movie that was poorly made, I would never be able to achieve it. I would have to unlearn so much basic film grammar" (The Flop House 10:18-10:40). Another user emphasizes the level of badness similarly: "This is a nugget of gold because of how incompetent everything is. If you set out to try and make a film this bad, you couldn't." His friend approves of him and says: "No, you'd fail at every turn" (BadTime Babble 27:13-27:27).

One of the first features that gets attacked is the plot. A user tries for several minutes to summarize the whole story, for the sake of clarity, but he still leaves out many important elements (RedLetterMedia 00:56:08-01:04:05). The sheer multiplicity of nuances and details makes the film a complete plot hole.

Dylan's best friend, Jim, has relationship problems with his wife Amy. She shoots him and passes it off as a suicide. Jim's teenage daughter has a crush on Dylan. When she tries to take a bath in his house, he warns her not to do this anymore. Dylan's wife Emily is addicted to painkillers. At some point she overdoses and dies. Dylan visits two therapists, and one of them keeps telling him that he has special powers. She was either a hallucination or a deitytype woman. This chain of plot cul-de-sacs ensures the impossibility of "fiction emotions." However, it is the high degree of incongruence that makes a badfilm more pleasurable. The fictional elements become transparent and the story transforms into an artifact. According to Lykins, badfilms "do not take the audience out of the narrative; rather the audiences are taken out of it" (14).

The film has many lines which enable quotation joyously. Lines like "It's a magical day!", "No more books!", "I cannot believe you committed suicide," "I resign today as president of the bank" or "I'm verry pissy!" are frequently performed by the viewers, who marvel over their artificiality and hollowness. A user emphasizes how "stilted" and "awkward" the dialogues are (Good Bad or Bad Bad 18:58-19:04). Another one scoffingly states that "there is no rhythm or purpose behind any of these dialogues" (Seen Any Movies Lately 03:44-03:49). A user 
refers to "president of the bank" line as "that is my favorite line in any movie ever" (Kurtis Conner 20:25-20:34). The lines usually get decontextualized from the script and become a tool of socialization. Fans use them to make each other laugh during or after the screening. The dialogues occupy an important place in a badfilm. ${ }^{3}$ The more quotability the film has, the higher the chances of it turning into a cult classic. During the participation-oriented screenings of cult films the audience shouts out lines.

Badfilms often do not have an ensemble of professionally cast actors or actresses. Dilettante but unskillful actors cannot deliver the lines with emotion and believability. Therefore, most of the performances end up being atrocious. In Fateful Findings, almost all actors, especially Breen, are subject to the mockery of the audience. Some users describe their acting as "porn acting." A user chastises the actors as follows: "Nobody acts like humans... They all act like weird mannequins or reptile people that are wearing the skin of humans" (The Flop House 19:28-19:36). Another user says that the film could be called "Dead Looks" and then a funny montage of the actors is shown (BadTime Babble 08:24-09:03). Bad acting exposes the artificiality of the art of cinema, almost in a Brechtian manner. It causes us to question the nature of a script and the function of the dialogues. A user emphasizes the bizarreness: "they are just saying random lines with no context" (Seen Any Movies Lately 05:21-05:24). The artefactual status of the narrative gains prominence rather than the content of the fiction.

Props and special effects have an importance for viewers in a badfilm. Neil Breen, who is responsible for visual design, as well as everything else about the film, inadvertently makes the effects more noticeable, whereas they should be the 'invisible' parts of a film. The rawness and the shoddiness render them clearly visible, and thus valuable in the eye of the viewers. Laptops, for instance, became a hallmark of the director and a running joke among Neil Breen fans. Dylan uses a few old laptops simultaneously-none of them is on. He does not hesitate to break them while having telenovela-style outbursts; "he hates these two laptops so much" remarks one user (Seen Any Movies Lately 06:00-06:03). In one scene, he tries not to spill his coffee whilst having a crisis in an exaggerated manner, but eventually he spills it on the laptop. This scene is cheerfully welcomed by almost all users. Another prop is the rough-hewn bandage on Dylan's face that he gets after the car accident. Users find the Phantom-of-the-Opera-like bandage hilarious because it is quite unrealistic (far from a decent bandage) and implausible (the oxygen mask is on the bandage where it shouldn't be). A user describes the enormous book, whose function is unclear but seems to be magical, as "ghost cake" (RedLetterMedia 01:03:37-01:03:47). Many users judgmentally gaze at set design. They banter about the carpeted floors in the hospital room or the room with walls covered in trash bags where Dylan is nude and cradling Leah. A shadowy smoke created by CGI, accompanied with a tense sound effect, is called a "fart cloud" by a user (Allison Pregler 33:46-33:49). Using stock footage and green screen is one of Neil Breen's the hallmarks. 
Even though Fateful Findings is the film with the least amount of these effects, the scenes they have been used in cannot escape being ridiculed by the users.

The users sometimes have strong, visceral responses to the film. Two users cruelly disdain Breen. One of them shows a picture of him and says: "He can barely think of anything, because there is no thought going through this head at any time." The other one continues: "It seemed like he wanted to make something that meant something, except he had no ideas" (Allison Pregler 04:58-05:20). The riffings occur as emotional displays of schadenfreude. One of the most watched videos about Neil Breen is full of ironic bashing. The user makes puns ("sheer Breenius," "suBreen being," "IMDBreen") and describes Fateful Findings as "one of the most magical film experiences of my entire life" (YourMovieSucksDOTorg 01:13-01:18). In the end, he reveals his schadenfreude: "Guys, his movies are so f...ing comedically exploitable, you have no idea!” (22:53-22:58).

According to Buckley, schadenfreude can be seen as the source or "the epitome of laughter" (219). A sense of superiority arises in the presence of the butt of the joke. In the context of badfilm, generally the butt appears to be the creator of the film, mostly due to his or her incompetence. ${ }^{4} \mathrm{~A}$ wide array of incongruities in the film creates amusement, which essentially arises through schadenfreude. In this regard, Neil Breen becomes most visible in the reaction videos of PewDiePie, whose channel on YouTube is the most-subscribed operated by an individual. The video in which he reviews Fateful Findings is called "THIS MAN IS GENIUS! (and here's why).” About the film, he says “it's painful to watch but it's also one of the funniest things you'll ever see” (PewDiePie 01:38-01:42). He goes through his favorite moments and makes jokes, puns, ironic and satirical remarks about nearly all the abovementioned things. Another user expresses his enjoyment derived from the film, without skipping disparagement: "This (the film) has, in terms of the laugh count for the amount of ridiculous nonsense that we would have laughed out loud at, I think this thing wins, hands down. But I still have absolutely no idea what the f...k any of it was about" (BadTime Babble 28:36-28:54).

Paracinematic reading is an act of subcultural resistance of sorts. However, like other subcultures, it "moves through a cycle of resistance and defusion" (Hebdige 130)commercialization and popularization may prevail in the course of time. YouTubers like PewDiePie may exploit badfilms for the sake of likes and view counts or the films may become valuable as subcultural capital for the fans. In the end, many reviewers end up saying about a badfilm that it is the "best movie ever" or a "masterpiece." This kind of enthroning is the sign of a film's transformation into a cult object, and a form of subcultural capital.

Some reviewers compared Fateful Findings to other badfilms. A user says: "You can have your Roomses and Birdemics" (The Flop House, 04:24-04:28); and reiterated that it is much better (or worse) than them. Church puts an annotation about the modern-day subcultural acts and states: "In our contemporary media landscape, most fan practices are not visible 
subcultural behaviours, but situational (though not casual) affective affinities with a range of cinematic texts" (16).

Lastly, our response to a badfilm is quite different if we see it on a small laptop by ourselves, or if we see it on a large TV with like-minded friends. The pleasure of watching a badfilm increases as it gets more crowded. Some reaction videos shot during the screenings of The Room, Birdemic, or Neil Breen's latest film, Twisted Pair, show that the audience usually watches these films with roaring laughter and schadenfreude outbursts. A user makes, for example, a remark about Fateful Findings" "party movie" status and adds: "it is definitely worth seeing a second time, with new friends and then we should have a party and invite people and watch Fateful Findings again" (Nyx Fears 28:39-28:49). The influence that other people have on the reception of badfilm is another issue worth examining in terms of subcultural practices.

\section{Conclusion}

This paper addresses why some bad films have irresistible appeal and the emotions by which they bring viewers together. The films that are considered 'so-bad-it's-good' could be regarded as subcultural entities as a consequence of their inherent properties and specific reception practices. The transformation of a bad film into a 'badfilm' can clearly be seen on social media, especially on YouTube, which gives a chance to film-buffs to share their thoughts and show their reactions. The cult interest in a badfilm relies heavily on the emotional engagement it begets. How could people appreciate and take pleasure in works that are bad (but somehow still good because of their flaws) is a question worth asking. In this context, the cult filmmaker Neil Breen's Fateful Findings and its various reviews were examined.

Fateful Findings, with its failures and overall incompetence, is a tour de force in badfilm making. A most convoluted plot, bizarre and irrelevant scenes, and bargain-priced special effects, unskilled acting performances: all these incongruous elements provoke viewers to resolve them and to make sense of the whole movie. They reveal the commonality of emotions shared by viewers. It is this common and colloquial aspect that eventually binds them together, and creates the conditions of a subcultural activity. I claim, therefore, that viewers obtain a sense-making practice from their engagement with badfilms.

The cinematic failures and bizarreness make badfilm appear intensely artificial. Viewers' emotional responses are evoked by the artefactual status of the film. It can be said that artifact emotions are a precondition for cult cinema. Seeing the film almost as an object is an important sign of its transformation into cult. At the same time, displaying certain emotional reactions becomes an unwritten law in badfilm milieu. Emotional performativity 
of schadenfreude has become an articulation of badfilm enthusiasm. Paracinematic artifact emotions can form social alliances and a certain kind of viewing strategy. A badfilm gains its value not only with its intrinsic qualities but also through social construction. The coherence of a badfilm is an attribute emanating from viewing practices and an emotional modus operandi.

\section{End Notes}

1. The concept is used in various phrases in literature and everyday language, such as "So-bad-it'sgood," "good-bad film" or "SOBIG". In this study, I chose to use "badfilm," following Hunter and Bartlett.

2. Nonetheless, Neil Breen's fans cherish his films by virtue of their 'so bad it's good' qualities. Breen himself denies that his films are 'midnight movies' and he frequently puts emphasis on their "legitimate, mainstream full-length" feature film qualities.

3. The Room (2003) has memorable lines, such as "You are tearing me apart Lisa!", "Oh hi Mark", "Anyway, how is your sex life?". Troll 2 (1990) has lines like "You can't piss on hospitality, I won't allow it!", "They're eating her... and then they're going to eat me... Oh my God!" which are frequently repeated by the fans.

4. Buckley also lays emphasis on philosopher Henri Bergson's apprehension of laughter. According to Bergson, the rigidity of a body or a character is the main source of all our laughter. They are "mechanical" and their actions "follow a determined program." As Buckley states, "the comic butt is machine-man. Our actions are risible to the exact extent that they remind us of a mechanical thing, and the most amusing people are those whose actions are least human and most mechanical" (220). Almost all the creators of badfilms meet this 'machine-man' trait. The films and the characters Tommy Wiseau, Neil Breen, and James Nguyen wrote seem to have a lack of basic human relations skills. It is quite possible to encounter viewers or critics claiming that these directors 'came from Mars' or are 'robots.'

\section{Works Cited}

BARTLETT, Becky. "'It Happens by Accident': Failed Intentions, Incompetence, and Sincerity in Badfilm," in Mathijs, Ernest and Jamie Sexton (eds.), The Routledge Companion to Cult Cinema. Routledge, 2020, pp. 40-49.

BRAY, Catherine. "One-star Wonders: How to Make a Film that's So Bad it's Good." The Guardian, 5 December 2020, https://www.theguardian.com/film/2020/dec/05/one-star-wonders-how-tomake-a-film-thats-so-bad-its-good. Accessed February 5, 2021.

BUCKLEY, F. H. "Schadenfreude and Laughter," in van Dijk, Wilco W. and Jaap W. Ouwerkerk (eds.), Schadenfreude Understanding Pleasure at the Misfortune of Others. Cambridge University Press, 2014, pp. 219-226. 
CHURCH, David. Grindhouse Nostalgia Memory, Home Video and Exploitation Film Fandom. Edinburgh University Press, 2015.

EBERT, Roger. "Pink Flamingos," in Sterritt, David and John Anderson (eds.), The B List: The National Society of Film Critics on the Low-Budget Beauties, Genre-Bending Mavericks, and Cult Classics We Love. De Capo Press, 2008, pp. 201-202.

GERAGHTY, Lincoln. "Authenticity, Popular Aesthetics and the Subcultural Politics of an Unwanted Blockbuster: The Case of Transformers," in Hubner, Laura (ed.), Valuing Films Shifting Perceptions of Worth, Palgrave Macmillian, 2011, pp. 88-105.

HEBDIGE, Dick. Subculture The Meaning of Style. Taylor \& Francis e-Library, 2002.

HOBERMAN, J. “Bad Movies.” Film Comment, vol. 16, no. 4, July-August 1980, pp. 7-12.

HUNTER, I. Q. (2014). “Trash Horror and the Cult of the Bad Film,” in Benshoff, Harry M. (ed.), A Companion to the Horror Film. John Wiley \& Sons, 2014, pp. 483-500.

JANCOVICH, Mark. "Cult Fictions: Cult Movies, Subcultural Capital and the Production of Cultural Distinctions.” Cultural Studies, vol. 16, no. 2, 2002, pp. 306-322.

KAWIN, Bruce. “After Midnight,” in Telotte, J. P. (ed.), The Cult Film Experience Beyond All Reason. The University of Texas Press, 1991, pp. 18-25.

KOLB, Kenneth H. “Emotional Subcultures.” Sociology Compass, vol. 8, no. 11, 2014, pp. 12291241.

LYKINS, Trey. The Use of Badness: Extratextuality in Bad Movies and Citationality in the Realist Aesthetic. MA Thesis, Faculty of the Graduate School of the University of Colorado, 2008.

PLANTINGA, Carl. Moving Viewers American Film and the Spectator's Experience. University of California Press, 2009.

---. "Putting Cognition in Its Place: Affect and the Experience of Narrative Film," in ThomsonJones, Katherine (ed.), Current Controversies in Philosophy of Film. Routledge, 2016, pp. 131-146. ---. Screen Stories Emotion and the Ethics of Engagement. Oxford University Press, 2018.

ROSS, Jaxen. Plot summary of Fateful Findings. IMDb, https://www.imdb.com/title/tt2332623/ plotsummary?ref_=tt_stry_pl. Accessed March 3, 2021.

SARKHOSH, Keyvan and Winfried Menninghaus. "Enjoying Trash Films: Underlying Features, Viewing Stances, and Experiential Response Dimensions.” Poetics, vol. 57, 2016, pp. 40-54.

SCONCE, Jeffrey. " 'Trashing' the Academy: Taste, Excess, and an Emerging Politics of Cinematic Style.” Screen, vol. 36, no. 4, 1995, pp. 371-393.

---. "Esper, the Renunciator: Teaching 'Bad' Movies to Good Students," in Jancovich, Mark et al. (eds.), Defining Cult Movies: The Cultural Politics of Oppositional Tastes, Manchester University Press, 2003, pp. 14-34.

---. "The Golden Age of Badness." Continuum, vol. 33, no. 6, 2019, pp. 666-676.

TAN, Ed S. Emotion and the Structure of Narrative Film: Film as an Emotion Machine. Erlbaum, 1996.

THORNTON, Sarah. "General Introduction," in Gelder, Ken and Sarah Thornton (eds.), The Subcultures Reader. Routledge, 1997, pp. 1-7. 
VAN DIJK, Wilco W., and Jaap W. Ouwerkerk. "Introduction to Schadenfreude," in van Dijk, Wilco W. and Jaap W. Ouwerkerk (eds.), Schadenfreude Understanding Pleasure at the Misfortune of Others. Cambridge University Press, 2014, pp. 1-13.

WATT SMITH, Tiffany. Schadenfreude, The Joy of Another's Misfortune. Hachette Book Group, 2018.

WEINER, Jonah. "The Worst Movies Ever Made. Birdemic, The Room, and what makes a horrible film great.” Slate, 6 April 2010, http://www.slate.com/articles/arts/culturebox/2010/04/the_ worst_movies_ever_made.html. Accessed March 8, 2021.

\section{Video Resources}

Allison Pregler. "Exposing the TRUTH with Fateful Findings! (Movie Nights) (ft. @Phelan Porteous).” YouTube, 11 March 2017, https://youtu.be/eryJDeVm4XY. Accessed February 8, 2021.

BadTime Babble. "Fateful Findings Review: Has Neil Breen made the best worst movie? So Bad It's Good | Badtimebabble.” YouTube, 24 December 2020, https://youtu.be/iHO1kbJLKus. Accessed March 6, 2021.

Film Courage. "Biggest Difference Between Bad Art and Great Art by UCLA Professor Richard Walter.” YouTube, 16 March 2015, https://youtu.be/D-GwRnBk-WY. Accessed March 16, 2021.

Good Bad or Bad Bad. “Good Bad or Bad Bad \#5 - Fateful Findings.” YouTube, 11 July 2016, https:// youtu.be/2iOCmQP6Ow4. Accessed April 2, 2021.

Homeless Movies. "FATEFUL FINDINGS [Review] I Can't Believe You've Done THIS Neil Breen! | Homeless Movies.” YouTube, 2 September 2019, https://youtu.be/Rbn1RLyLp4s. Accessed March 28, 2021.

Kurtis Conner. "Fateful Findings: An Extremely Weird Movie.” YouTube, 31 May 2019, https:// youtu.be/q9VkIgFmxuk. Accessed April 8, 2021.

Nyx Fears. "That Weird B-Movie Show: Fateful Findings | Episode 2.” YouTube, 18 September 2015, https://youtu.be/mEBHTcXQ4mk. Accessed February 18, 2021.

PewDiePie. “THIS MAN IS GENIUS! (and here's why).” YouTube, 16 March 2017, https://youtu. be/iQzJzqHO4b0. Accessed May 12, 2021.

RedLetterMedia. "Best of the Worst: Wheel of the Black Spine Plinketto." YouTube, 23 April 2021, https://youtu.be/M2MgjPrSVX0. Accessed May 12, 2021.

Seen Any Movies Lately. "Fateful Findings Reaction video.” YouTube, 14 May 2020, https://youtu. be/BJiSkLw1Y6k. Accessed April 12, 2021.

The Flop House. "The Flop House \#187-Fateful Findings.” YouTube, 23 August 2016, https:// youtu.be/ba1GpfXVlMc. Accessed April 23, 2021.

YourMovieSucksDOTorg. "YMS: Neil Breen.” YouTube, 13 December 2017, https://youtu. be/6L4g3H_TM28. Accessed May 12, 2021. 